\title{
In vitro Antioxidant Activity of Mangifera indica Leaf Extracts
}

\author{
Kimihisa Itoh ${ }^{1}$, Tetsuya Matsukawa ${ }^{1,3}$, Mamoru Okamoto $^{2}$, Kanasa Minami ${ }^{2}$, Norimichi Tomohiro ${ }^{1}$, Kosuke \\ Shimizu $^{1}$, Shin'ichiro Kajiyama ${ }^{3}$, Yuichi Endo ${ }^{1,2}$, Hideaki Matsuda ${ }^{2,4}$ \& Shigeru Shigeoka ${ }^{1}$ \\ ${ }^{1}$ The Experimental Farm, Kindai University, Wakayama, Japan \\ ${ }^{2}$ Faculty of Pharmacy, Kindai University, Osaka, Japan \\ ${ }^{3}$ Faculty of Biology-Oriented Science and Technology, Kindai University, Wakayama, Japan \\ ${ }^{4}$ The late professor, Kindai University, Osaka, Japan \\ Correspondence: Kimihisa Itoh, The Experimental Farm, Kindai University, 2355-2 Yuasa, Yuasa-cho, Arida-gun, \\ Wakayama 643-0004, Japan. Tel: 81-737-622-953. E-mail: itoh_k@nara.kindai.ac.jp
}

Received: May 14, 2020

doi:10.5539/jps.v9n2p39
Accepted: June 5, $2020 \quad$ Online Published: June 26, 2020

URL: https://doi.org/10.5539/jps.v9n2p39

\begin{abstract}
In this study, we aimed to identify the utility of pruned mango (Mangifera indica 'Irwin') leaves as a resource for ingredients with antioxidant activity. Firstly, we examined the antioxidant activity of extracts obtained from the pericarps, flesh, flowers, barks, seeds, young dark reddish brown leaves (YDL-ext), young yellow leaves (YYL-ext), and pruned old dark green leaves (OML-ext) obtained from 'Irwin' mango. Among them, methanolic extract of flower and OML-ext showed the most potent 1,1-diphenyl-2-picrylhydrazyl (DPPH) radical scavenging and superoxide dismutase (SOD)-like activity. The flesh extract showed weak DPPH radical scavenging activity, but did not show SOD-like activity. Secondly, we investigated the relationship between the maturation of leaves and their antioxidant activity by considering the contents of their two active polyphenolic components, 3-C- $\beta$-D-glucosyl-2,4,4',6-tetrahydroxybenzophenone (1) and mangiferin (2), in addition to chlorophyll (3) and anthocyanins represented by cyanidin-3-O-glucoside (4). The DPPH radical scavenging activity of YDL-ext, YYL-ext and OML-ext were mainly attributable to 1, 2 and $\mathbf{3}$, whereas their SOD-like activity was partly attributable to $\mathbf{2}$. The DPPH radical scavenging and SOD-like activities of YDL-ext and YYL-ext were attributable to $\mathbf{1}$ and $\mathbf{2}$. These activities were also due to anthocyanins whose content is highest in YDL-ext. Considering the amounts of leaves obtained from pruning, old dark green leaves may be a reasonable natural resource for preparing cosmetics and/or supplemental ingredients with health-enhancing properties, antioxidant activity and inhibitory effect on AGEs formation and pancreatic lipase.
\end{abstract}

Keywords: anthocyanin, antioxidation, chlorophyll, DPPH radical scavenging activity, 3-C- $\beta$-D-glucosyl-2,4,4',6-tetrahydroxybenzophenone, Mangifera indica 'Irwin', mangiferin, SOD-like activity

\section{Introduction}

Mango is one of the most important fruits with more than 1000 cultivars cultivated worldwide. Pruning is an essential component for cultivation of mango fruits. Pruned leaves have hitherto been considered unusable and were thus discarded. Therefore, in the course of our ongoing research to find novel functions of mango leaves, we first focused on the pruned leaves of the mango. We have previously reported that the methanolic extract of pruned old dark green leaves of mango (OML-ext) exhibited inhibitory effects on advanced glycation end products (AGEs) formation and pancreatic lipase (Itoh et al., 2016 and 2017).

Recently, it has been shown that antioxidants play an important role in preventing oxidative stress-related diseases and aging. Numerous data on the antioxidant activities of various plant materials have been reported. In the case of mango, Jose et al. (2018) reported that the ethanolic extracts of mango leaves exhibited antioxidant effects through 1,1-diphenyl-2-picrylhydrazyl (DPPH) radical scavenging and superoxide dismutase (SOD)-like activities with half maximal inhibitory concentration $\left(\mathrm{IC}_{50}\right.$ ) values of 14.94 and $68.0 \mathrm{mg} / \mathrm{mL}$, respectively. Another report by Udem, Dahiru, and Etteh (2018) revealed that leaf ethanolic extracts showed the highest percentage of antioxidant activity with $79.09 \%$ at $100 \mathrm{mg} / \mathrm{mL}$. According to the report by Fidrianny, Rahmiyani, and Wirasutisna (2013), the ethanolic extract of mango leaf showed potent DPPH radical scavenging activity with $\mathrm{IC}_{50}<50 \mathrm{ppm}(\leq 50 \mu \mathrm{g} / \mathrm{mL})$. Although, there are several reports concerning the antioxidant activity of mango leaf extract as described above, there is a large discrepancy between the data reported on the potency of 
antioxidant activity. If the antioxidant activity of OML-ext is confirmed, the utility of pruned old dark green leaves for the preparing cosmetics and/or supplemental ingredients with health-enhancing properties may be increased.

In traditional medicine, the different parts of mango such as seeds, leaves, and bark have been used for their health properties (Lauricella, Emanuele, Calvaruso, Giuliano, \& D'Anneo, 2017).

Firstly, these interesting bibliographies have inspired us to examine the antioxidant activity of the methanolic extracts of several parts such as pericarps, flesh, flowers, bark, seeds, from the mango cultivar 'Irwin' cultivated in the Experimental Farm of Kindai University. Since mango is an evergreen plant, leaves at different three stages of growth, young dark reddish brown leaves, young yellow leaves and pruned old dark green leaves, were collectable during pruning at the same time in late summer. This prompted us to examine the relationship between the maturation of leaves and these antioxidant activities. To the best of our knowledge, there has been no investigation of the relationship between mango leaves maturation and their antioxidant activities by considering the content of their four chemical components, two polyphenolic components, 3-C- $\beta$-D-glucosyl-2,4,4',6-tetrahydroxybenzophenone (1) and mangiferin (2), in addition to chlorophyll (3) and anthocyanins represented by cyanidin-3-O-glucoside (4).

\section{Materials and Method}

\subsection{Plant Materials}

The pericarps, flesh, flowers, bark, seeds, and pruned old dark green leaves of Mangifera indica 'Irwin' were collected from the Experimental Farm of Kindai University $\left(34^{\circ} 2^{\prime} \mathrm{N}, 135^{\circ} 11^{\prime} \mathrm{E}, 17 \mathrm{~m} \mathrm{ASL}\right)$, located in Wakayama Prefecture, Japan (Figure 1). The $M$. indica trees planted in the ground are commercially grown in a plastic greenhouse under controlled conditions (temperature: winter, min. $2^{\circ} \mathrm{C}$ (room) and $10^{\circ} \mathrm{C}$ (soil); summer, max. $35^{\circ} \mathrm{C}$ (room) and $31^{\circ} \mathrm{C}$ (soil)). 'Irwin' mango is a representative cultivar especially in Japan and Taiwan because of its early ripening and relatively good resistance to cold weather.

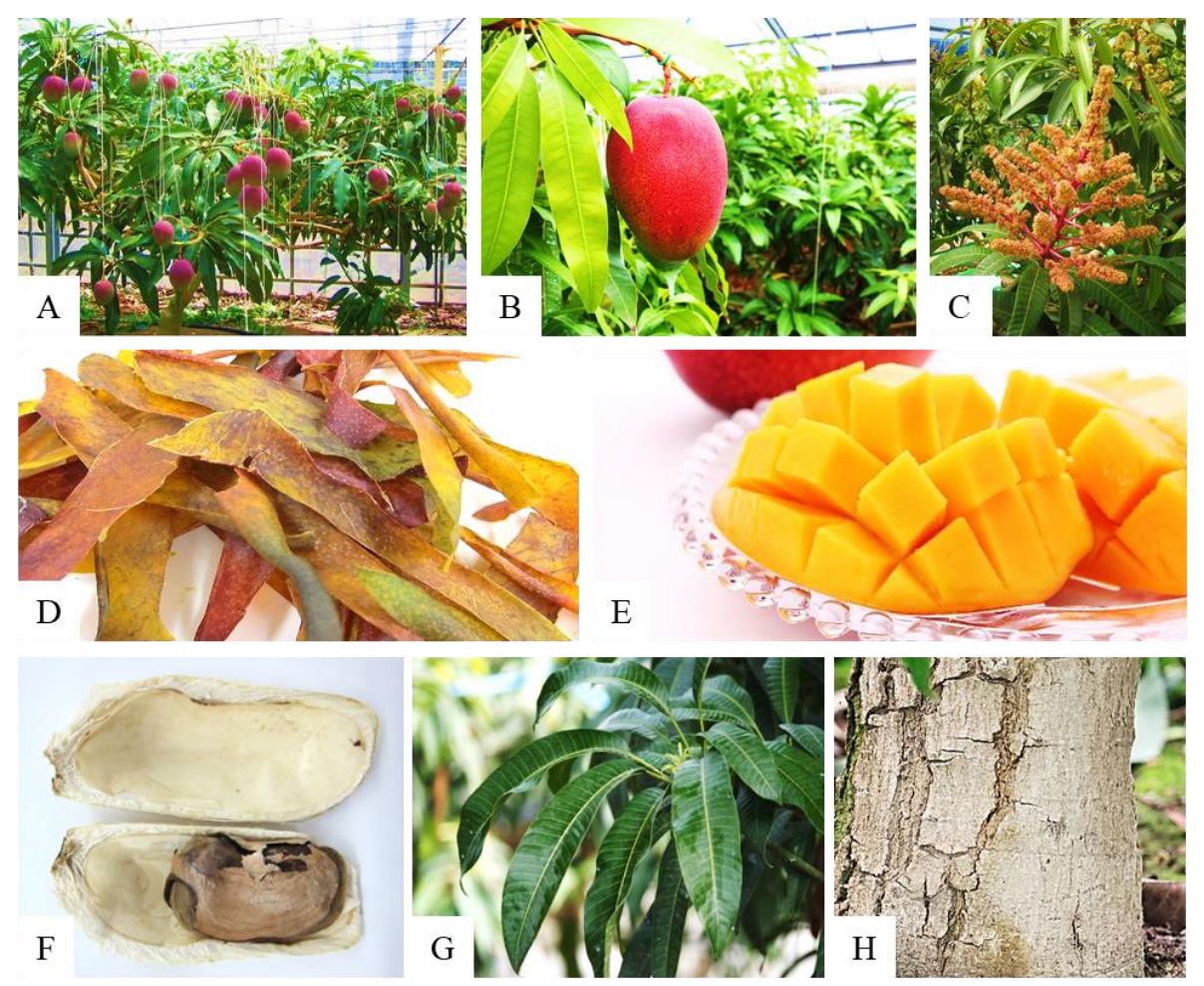

The picture of A, Irwin mango tree with several fruits in a greenhouse, Kindai University; B, fruit; C, flowers; D, pericarps; E, flesh; F, seed; G, old dark green leaves; H, bark.

Figure 1. Fruit, flowers, pericarps, flesh, seed, old dark green leaves and bark of 'Irwin' mango prepared in the experiment 
Three kinds of mango leaves (old dark green leaf, young dark reddish brown leaf, and young yellow leaf) were collected from 250 mango trees which were propagated by grafting (height of trees: $2 \mathrm{~m}$, age of trees: 18-26 years old, life span of trees: 40-50 years). The materials (old dark green leaves, young dark reddish brown leaves, and young yellow leaves) were collected in August 2015 and August 2016. These young and old leaves were collected together at the time of pruning in late summer which was possible as mango is an evergreen plant. The collected leaves were visually classified by color into three groups, namely young dark reddish brown, young yellow, and old dark green leaves as illustrated in our previous papers (Itoh et al., 2016 and 2017). The samples were identified by the Experimental Farm of Kindai University, air-dried at $50^{\circ} \mathrm{C}$ for $72 \mathrm{~h}$ in an automatic air-drying apparatus (Vianove Inc., Tokyo, Japan), and powdered. Voucher specimens of pericarps, flesh, flowers, bark, seeds and leaves (Mango old leaf, OML201508DG-S and OML201608DG-S; Mango young dark reddish brown leaf, YML201508DB-S; Mango young yellow leaf, YML201508Y-S) are deposited at the Experimental Farm, Kindai University.

\subsection{Extraction}

Methanolic extracts of young dark reddish brown leaves (YDL-ext), young yellow leaves (YYL-ext), and old dark green leaves (OML-ext) were obtained according to the previous paper (Itoh et al., 2016). The yields of the methanolic extract obtained from pericarps, flesh, flowers, bark and seeds of $M$. indica 'Irwin' were 23\%, 63\%, $25 \%, 19 \%$, and $6 \%$, respectively.

\subsection{Reagents}

The chemical and biochemical reagents used in this study were of reagent grade and were purchased from Wako Pure Chemical Industries, Ltd. (Osaka, Japan) and/or Nacalai Tesque, Inc. (Kyoto, Japan) unless otherwise noted.

\subsection{In vitro Radical Scavenging Activity}

Radical scavenging activity was measured according to the method outlined by Blois (1958) with minor modifications described in a previous paper (Itoh et al., 2009). Briefly, the test sample was dissolved in DMSO and diluted with $0.5 \mathrm{M}$ acetate buffer ( $\mathrm{pH} 5.5$ ) to a final DMSO concentration of 5\% v/v. A mixture of test sample solution $(2 \mathrm{~mL}), \mathrm{EtOH}(1.6 \mathrm{~mL}), 0.5 \mathrm{M}$ acetate buffer $(0.4 \mathrm{~mL})$, and $0.5 \mathrm{mM} \mathrm{DPPH} / \mathrm{EtOH}$ solution $(1.0 \mathrm{~mL})$ was allowed to stand for $30 \mathrm{~min}$ at room temperature. The OD of the resulting mixture was determined with a spectrophotometer at $520 \mathrm{~nm}$. L-Ascorbic acid was used as a reference agent. The scavenging activity of each sample was expressed as the percentage of the decrease in OD compared with that of control DPPH solution. The $\mathrm{IC}_{50}$ value represents the concentration of sample required to scavenge $50 \%$ of DPPH free radicals. Each assay was performed in triplicate $(P$-value $<0.01)$.

\subsection{In vitro SOD-Like Activity}

SOD-like activity was measured according to the method outlined by Oyanagui (1984) with minor modifications described in a previous paper (Itoh et al., 2009). Briefly, the test sample was dissolved in DMSO and diluted with $0.5 \mathrm{mM}$ disodium dihydrogen ethylenediamine tetraacetate (EDTA)-PBS buffer ( $\mathrm{pH} \mathrm{8.2)}$ to a final DMSO concentration of $1 \% \mathrm{v} / \mathrm{v}$. SOD, as a reference, originating from cow's milk (Roche Co., Tokyo, Japan), was dissolved with the buffer. A mixture of the buffer $(0.2 \mathrm{~mL}), 0.5 \mathrm{mM}$ hypoxanthine in the buffer $(0.2 \mathrm{~mL})$, reagent A solution (10 mM hydroxylamine hydrochloride and $1 \mathrm{mg} / \mathrm{mL}$ hydroxylamine- $o$-sulfonic acid in water) $(0.1 \mathrm{~mL})$, water $(0.2 \mathrm{~mL})$, and the sample solution $(0.1 \mathrm{~mL})$ was preincubated at $37^{\circ} \mathrm{C}$ for $10 \mathrm{~min}$. Five $\mathrm{mU} / \mathrm{mL}$ xanthine oxidase (Roche Co., Tokyo, Japan) solution in the buffer $(0.2 \mathrm{~mL})$ was added to the above solution, and the mixture was incubated at $37^{\circ} \mathrm{C}$ for $30 \mathrm{~min}$. Reagent B $(30 \mu \mathrm{M} \mathrm{N}$-1-naphthylethylenediamine $\cdot 2 \mathrm{HCl}, 3 \mathrm{mM}$ sulfanilic acid, and $25 \%$ acetic acid in water) $(2 \mathrm{~mL})$ was added to the reaction mixture. The resulting mixture was allowed to stand for $30 \mathrm{~min}$ at room temperature, and then OD was measured at $550 \mathrm{~nm}$ with a spectrophotometer. The SOD-like activity of each sample was expressed as the percentage of the decrease in OD compared with that of control A or B solution. The $\mathrm{IC}_{50}$ value represents the concentration of sample required to scavenge $50 \%$ of the superoxide anions produced by the hypoxanthine-xanthine oxidase system. Each assay was performed in triplicate $(P$-value $<0.01)$.

\subsection{Determination of Content of 1, 2, 3 and 4 in Each Mango Cultivar Leaf Extract}

In this paper, determination of each compound in the leaf extracts was performed in triplicate, and the values are represented as the mean \pm standard deviation. The HPLC determination method for the contents $(\mathrm{mg} / \mathrm{g}$ extract) of 1 and 2 in each mango leaf extract was described in a previous paper (Itoh et al., 2016). Spectrophotometric determination of the content of $\mathbf{3}$ (mg/g extract) was carried out according to the method given by Porra, Thompson, and Kriedemann (1989). The content of total anthocyanin $(\mu \mathrm{g} / \mathrm{g}$ extract) in each leaf extract was 
determined by the HPLC analysis described in a previous paper (Itoh et al., 2017).

\subsection{Statistical Analysis}

The experimental data were evaluated for statistical significance using Bonferroni/Dunn's multiple-range test with GraphPad Prism for Windows, Ver. 5 (GraphPad Software Inc., 2007; Armonk, NY, USA).

\section{Results and Discussion}

\subsection{Antioxidant Activity of the Extracts Obtained from Pericarps, Flesh, Flowers, Bark, Seeds and Pruned Old Dark Green Leaves (OML-ext)}

We examined the in vitro antioxidant activity of the extracts obtained from several parts of 'Irwin' mango such as pericarps, flesh, flowers, bark, seeds and pruned old dark green leaves by two assays that estimated the DPPH radical scavenging and SOD-like activities. 'Irwin' mangoes are commercially grown in a plastic greenhouse, and all parts of mango were collected from the Experimental Farm of Kindai University (Photo 1) for preparation of each extract. Among them, flower extract and OML-ext showed more potent DPPH radical scavenging and SOD-like activities than the other extracts as shown in Table 1. The DPPH radical scavenging activity of flesh extract was weak, but the extract did not show SOD-like activity. The scavenging activity of seed extract against DPPH radical was active, whereas the SOD-like activity was very weak. Moreover, the SOD-like activities of pericarps extract and bark extract were also weak. The DPPH radical scavenging activity assay method has been widely used to evaluate the radical scavenging activity of plant extracts and their constituents, and the $\mathrm{IC}_{50}$ value represents the concentration of sample required to scavenge for $50 \%$ of DPPH free radicals (Hou et al., 2003). The scavenging activity was evaluated using L-ascorbic acid $\left(\mathrm{IC}_{50}, 22 \mu \mathrm{M}\right)$, a reference agent, whose $\mathrm{IC}_{50}$ was in accordance with our reported $\mathrm{IC}_{50}$ value $(30 \mu \mathrm{M})$ (Itoh et al., 2009). In SOD-like activity assay, SOD was used as a reference agent, the $\mathrm{IC}_{50}$ value of SOD was $0.2 \mathrm{U} / \mathrm{mL}$ in accordance with our reported $\mathrm{IC}_{50}$ value $(0.2 \mathrm{U} / \mathrm{mL})$ (Itoh et al., 2009). Considering the potency of the activity of leaf extract in preliminary examination, and the amounts of leaves obtained from pruning, old dark green leaves may be a reasonable natural resource for the preparation of ingredients with antioxidant activity.

Table 1. $\mathrm{IC}_{50}$ values of DPPH radical scavenging and SOD-like activities of $\mathrm{MeOH}$ extracts obtained from 'Irwin' mango leaves, flowers, pericarps, seeds, bark and flesh

\begin{tabular}{lll}
\hline Samples & $\begin{array}{l}\text { DPPH radical scavenging activity } \\
(\mu \mathrm{g} / \mathrm{mL} \text { or } \mu \mathrm{M})\end{array}$ & $\begin{array}{l}\text { SOD-like activity } \\
(\mu \mathrm{g} / \mathrm{mL} \text { or } \mathrm{U} / \mathrm{mL})\end{array}$ \\
\hline Leaf extract (OML-ext) & $9 \mu \mathrm{g} / \mathrm{mL}$ & $117 \mu \mathrm{g} / \mathrm{mL}$ \\
Flower extract & $3 \mu \mathrm{g} / \mathrm{mL}$ & $171 \mu \mathrm{g} / \mathrm{mL}$ \\
Pericarp extract & $11 \mu \mathrm{g} / \mathrm{mL}$ & $760 \mu \mathrm{g} / \mathrm{mL}$ \\
Seed extract & $4 \mu \mathrm{g} / \mathrm{mL}$ & $888 \mu \mathrm{g} / \mathrm{mL}$ \\
Bark extract & $12 \mu \mathrm{g} / \mathrm{mL}$ & $656 \mu \mathrm{g} / \mathrm{mL}$ \\
Flesh extract & $768 \mu \mathrm{g} / \mathrm{mL}$ & N.E. ${ }^{\text {c) }}$ \\
L-Ascorbic acid & $22 \mu \mathrm{M}$ & N.D. ${ }^{\text {d) }}$ \\
SOD & N.D. ${ }^{\text {d) }}$ & $0.2 \mathrm{U} / \mathrm{mL}$ \\
\hline
\end{tabular}

${ }^{\text {a) }} \mathrm{IC}_{50}$ value represents the concentration of sample required to inhibit $50 \%$ of DPPH free radical; ${ }^{\text {b) }} \mathrm{IC}_{50}$ value represents the concentration of sample required to inhibit $50 \%$ of superoxide anions; ${ }^{\text {c) }}$ N.E.: no effect; ${ }^{\text {d) }}$ N.D.: not determined.

\subsection{Relationship between Leaves Maturation and Their Antioxidant Activities}

We investigated the relationship between leaves maturation and their antioxidant activities by considering the content of their two active polyphenolic components, 3-C- $\beta$-D-glucosyl-2,4,4',6-tetrahydroxybenzophenone (1) and mangiferin (2), in addition to the content of chlorophyll (3) and anthocyanins represented by cyanidin-3-O-glucoside (4). The antioxidant activities of these four major components of mango leaves were examined and the results were depicted in Table 2 . The collected leaves were visually classified by color into three groups as described in the previous paper (Itoh et al., 2017). The antioxidant activity of the extract of three stage of leaves maturation of mango leaves (young dark reddish brown leaves (YDL-ext), young yellow leaves (YYL-ext) and old dark green leaves (OML-ext)) is shown in Table 3. The antioxidant activity of OML-ext was superior to those of YDL-ext and YYL-ext, and the activities of these extracts were slightly increased when the leaves matured from yellow to dark green. As for the active ingredients that reportedly inhibit AGEs formation, 
the activity-guided fractionation of OML-ext using these assays and HPLC analysis led to the isolation of $\mathbf{1}, \mathbf{2}$ and $\mathbf{3}$ as one of the active constituents of OML-ext, and 1, 2 and $\mathbf{4}$ as one of the active constituents of YDL-ext and YYL-ext (Itoh et al., 2017; Itoh et al., 2020). Moreover, further HPLC analysis revealed that the contents (mg/g or $\mu \mathrm{g} / \mathrm{g}$ extract) of $\mathbf{1}, \mathbf{2}, \mathbf{3}$ and $\mathbf{4}$ in these leaf extracts were high as shown in Table 4. As a result, the DPPH radical scavenging activity of YDL-ext, YYL-ext and OML-ext was partly attributable to $\mathbf{1}, \mathbf{2}$ and $\mathbf{3}$, and their SOD-like activity was partly attributable to 2 . The DPPH radical scavenging and SOD-like activities of YDL-ext and YYL-ext were due to anthocyanins represented by $\mathbf{4}$ whose content is higher in young mango leaves. Considering the potent activity of leaf extract in preliminary examination, and the amounts of leaves obtained from pruning, old dark green leaves may be a reasonable natural resource for preparing ingredients with antioxidant activity. These findings identified the utility of the old dark green mango leaves considering with the potent activity of leaf extract in preliminary examination, and with the amounts of leaves obtained from pruning, thus the pruned old dark green mango leaves may be a reasonable natural resource for preparing ingredients with antioxidant activity.

Malherbe et al. (2014) have reported that no radical scavenging was observed for 1, when isolated from shoots of Cyclopia genistoides, using the on-line HPLC-DPPH assay, whereas $\mathbf{2}$ had high activity against DPPH radical in our experiments. Because they did not use a reference compound such as L-ascorbic acid or $\alpha$-tocopherol, it is difficult to discuss the reasons here. We assumed that the discrepancy of the activity of $\mathbf{1}$ might be partially due to some differences in experimental conditions, such as evaluation method. Accordingly, this is the first report on DPPH radical scavenging and SOD-like activities of $\mathbf{1}$. On the other hand, the potent inhibitory activity of leaf extracts cannot exclude a hypothesis that other ingredients may also contribute to the activity. To identify other active ingredients, further studies are required, which are now ongoing.

Table 2. $\mathrm{IC}_{50}$ values of DPPH radical scavenging and SOD-like activities of 3-C- $\beta$-D-glucosyl-2,4,4',6-tetrahydroxybenzophenone (1), mangiferin $\quad(2), \quad$ chlorophyll $\quad$ (3) and cyanidin-3-O-glucoside (4)

\begin{tabular}{lll}
\hline Samples & $\begin{array}{l}\text { DPPH radical scavenging activity } \\
(\mu \mathrm{M} \text { or } \mu \mathrm{g} / \mathrm{mL})\end{array}$ & $\begin{array}{l}\text { SOD-like activity }^{\mathrm{b})} \\
(\mu \mathrm{M} \text { or U/mL) }\end{array}$ \\
\hline $\mathbf{1}$ & $74 \mu \mathrm{M}$ & N.E. $^{\text {c) }}$ \\
$\mathbf{2}$ & $12 \mu \mathrm{M}$ & $872 \mu \mathrm{M}$ \\
$\mathbf{3}$ & $224 \mu \mathrm{g} / \mathrm{mL}$ & N.E. $^{\mathrm{c})}$ \\
$\mathbf{4}$ & $6 \mu \mathrm{M}$ & $196 \mu \mathrm{M}$ \\
L-Ascorbic acid & $22 \mu \mathrm{M}$ & N.D. ${ }^{\mathrm{d})}$ \\
SOD & N.D. & $0.2 \mathrm{U} / \mathrm{mL}$ \\
\hline
\end{tabular}

a) $\mathrm{IC}_{50}$ value represents the concentration of sample required to inhibit $50 \%$ of DPPH free radical; ${ }^{\text {b) }} \mathrm{IC}_{50}$ value represents the concentration of sample required to inhibit $50 \%$ of superoxide anions. ${ }^{\text {c) }}$ N.E.: no effect, ${ }^{\text {d) }}$ N.D.: not determined.

Table 3. $\mathrm{IC}_{50}$ values of DPPH radical scavenging and SOD-like activities of MeOH extracts of young dark reddish brown, young yellow and old dark green mango leaves

\begin{tabular}{lll}
\hline Samples & $\begin{array}{l}\text { DPPH radical scavenging activity } \\
(\mu \mathrm{g} / \mathrm{mL} \text { or } \mu \mathrm{M})\end{array}$ & $\begin{array}{l}\text { SOD-like activity }{ }^{\mathrm{b})} \\
(\mu \mathrm{g} / \mathrm{mL} \text { or U/mL) }\end{array}$ \\
\hline Young dark reddish brown leaf extract (YDL-ext) & $29 \mu \mathrm{g} / \mathrm{mL}$ & $141 \mu \mathrm{g} / \mathrm{mL}$ \\
Young yellow leaf extract (YYL-ext) & $15 \mu \mathrm{g} / \mathrm{mL}$ & $138 \mu \mathrm{g} / \mathrm{mL}$ \\
Old dark green leaf extract (OML-ext) & $9 \mu \mathrm{g} / \mathrm{mL}$ & $117 \mu \mathrm{g} / \mathrm{mL}$ \\
L-Ascorbic acid & $22 \mu \mathrm{M}$ & $\mathrm{N} . \mathrm{D} .^{\mathrm{c})}$ \\
SOD & N.D. & $0.2 \mathrm{U} / \mathrm{mL}$ \\
${ }^{\mathrm{a})} \mathrm{IC}_{50}$ value represents the concentration of sample required to inhibit $50 \%$ of DPPH free radical; ${ }^{\text {b) }} \mathrm{IC}_{50}$ value \\
represents the concentration of sample required to inhibit $50 \%$ of superoxide anions. ${ }^{\text {c) }}$ N.D.: not determined.
\end{tabular}


Table 4. The contents of 3-C- $\beta$-D-glucosyl-2,4,4',6-tetrahydroxybenzophenone (1), mangiferin (2), chlorophyll (3) and cyanidin-3-O-glucoside (4) in YDL-ext, YYL-ext and OML-ext

\begin{tabular}{lcccc}
\hline Samples & $\mathbf{1}(\mathrm{mg} / \mathrm{g}$ extract) & $\mathbf{2}(\mathrm{mg} / \mathrm{g}$ extract) & $\mathbf{3}(\mathrm{mg} / \mathrm{g}$ extract $)$ & $\mathbf{4}(\mu \mathrm{g} / \mathrm{g}$ extract $)$ \\
\hline YDL-ext & $400.0 \pm 11.0 \mathrm{mg} / \mathrm{g}$ & $78.6 \pm 1.2 \mathrm{mg} / \mathrm{g}$ & $0.85 \pm 0.002 \mathrm{mg} / \mathrm{g}$ & $7.38 \pm 0.24 \mu \mathrm{g} / \mathrm{g}$ \\
YYL-ext & $278.6 \pm 15.5 \mathrm{mg} / \mathrm{g}$ & $79.4 \pm 1.0 \mathrm{mg} / \mathrm{g}$ & $2.18 \pm 0.004 \mathrm{mg} / \mathrm{g}$ & $5.80 \pm 0.59 \mu \mathrm{g} / \mathrm{g}$ \\
OML-ext & $205.9 \pm 7.6 \mathrm{mg} / \mathrm{g}$ & $85.1 \pm 0.5 \mathrm{mg} / \mathrm{g}$ & $4.34 \pm 0.017 \mathrm{mg} / \mathrm{g}$ & N.D. ${ }^{\mathrm{a})}$
\end{tabular}

YDL-ext: young dark reddish brown leaf extract, YYL-ext: young yellow leaf extract, OML-ext: old dark green leaf extract. ${ }^{\text {a) }}$ N.D.: not detected.

\section{Conclusion}

The antioxidant activity of the extracts obtained from several parts of pericarps, flesh, flowers, bark, seeds and old dark green leaves obtained from Mangifera indica 'Irwin' was examined by evaluating DPPH radical scavenging and SOD-like activities. Among them, flower extract and OML-ext showed more potent DPPH radical scavenging and SOD-like activities than those of other extracts. Considering the potency of the activity of leaf extract in preliminary examination, and the amounts of leaves obtained from pruning, old dark green leaves may be a reasonable natural resource for the preparation of ingredients with antioxidant activity. Among the comparison in the activities between YDL-ext, YYL-ext and OML-ext, both activities of OML-ext were superior to those of YDL-ext and YYL-ext, while the activities of these extracts were slightly increased in accordance with the maturation of the leaves from yellow to dark green. The DPPH radical scavenging activity of YDL-ext, YYL-ext and OML-ext was partly attributable to $\mathbf{1 , 2}$ and $\mathbf{3}$, and their SOD-like activity was partly attributable to 2. The DPPH radical scavenging and SOD-like activities of YDL-ext and YYL-ext might be partially due to the higher anthocyanin content in young mango leaves. This is the first report on DPPH radical scavenging and SOD-like activities of $\mathbf{1}$. Hitherto, pruned mango leaves were unworthy and discarded during the cultivation process of mango fruits. Thus, from the viewpoint of utility of mango leaves, the pruned old dark green leaves may be a reasonable natural resource for the preparation of cosmetics and/or supplemental ingredients with health-enhancing properties and antioxidant activity in addition to the known inhibitory effects on AGEs formation (Itoh et al., 2017) and pancreatic lipase (Itoh et al., 2016). Confirming the antioxidant activity of mango leaf increased the utility of the pruned mango leaves. However, further investigations are required to examine the safety of administration and the mechanisms involved and also to reveal other active constituents.

\section{Acknowledgments}

We are grateful to the technical staff of Yuasa Experimental Farm, Kindai University for the collection of mango leaves. We are also deeply grateful to Dr. Shunsuke Naruto for his invaluable guidance and advice. We would like to thank Editage (www.Editage.com) for English language editing.

\section{References}

Blois, M. S. (1958). Antioxidant determinations by the use of a stable free radical. Nature, 181, 1199-1200. https://doi.org/10.1038/1811199a0

Fidrianny, I., Rahmiyani, I., \& Wirasutisna, R. K. (2013). Antioxidant capacities from various leaves extracts of four varieties mangoes using DPPH, ABTS assays and correlation with total phenolic, flavonoid, carotenoid. International Journal of Pharmacy and Pharmaceutical Sciences, 5(4), 189-194.

Hou, W. C., Lin, R. D., Cheng, K. T., Hung, Y. T., Cho, C. H., Chen, C. H., ... Lee, M. H. (2003). Free radical-scavenging activity of Taiwanese native plants. Phytomedicine, 10, 170-175. https://doi.org/10.1078/094471103321659898

Itoh, K., Hirata, N., Masuda, M., Naruto, S., Murata, K., Wakabayashi, K., \& Matsuda, H. (2009). Inhibitory effects of Citrus hassaku extract and its flavanone glycosides on melanogenesis. Biological and Pharmaceutical Bulletin, 32(3), 410-415. https://doi.org/10.1248/bpb.32.410

Itoh, K., Murata, K., Nakagaki, Y., Shimizu, A., Takata, Y., Shimizu, K., ... Matsuda, H. (2016). Inhibitory activity of Mangifera indica leaf extract on pancreatic lipase. Journal of Plant Studies, 5(2), 72-78. https://doi.org/10.5539/jps.v5n2p72

Itoh, K., Murata, K., Sakaguchi, N., Akai, K., Yamaji, T., Shimizu, K., ... Matsuda, H. (2017). Inhibition of advanced glycation end products formation by Mangifera indica leaf extract. Journal of Plant Studies, 6(2), 102-107. https://doi.org/10.5539/jps.v6n2p102 
Itoh, K., Matsukawa T., Minami K., Okamoto M., Tomohiro N., Shimizu K., ... Shigeoka S. (2020). Inhibitory effect of several Mangifera indica cultivar leaf extracts on the formation of advanced glycation end products (AGEs). Journal of Plant Studies, 9(2), 33-38. https://doi.org/doi:10.5539/jps.v9n2p33

Jose, M., Varghese, I. V., Jayakar, V., Lokapur, V., Srinivasa, K., \& Shantaram, M. (2018). Evaluation of antioxidant activities and free radical scavenging properties in mango leaves, husks of areca and coconut. Research Journal of Pharmaceutical, Biological and Chemical Sciences, 9(4), 1607-1619.

Lauricella, M., Emanuele, S., Calvaruso, G., Giuliano, M., \& D’Anneo, A. (2017). Multifaceted health benefits of Mangifera indica L. (Mango): The inestimable value of orchards recently planted in Sicilian rural areas. Nutrients, 9(5), 525-538. https://doi.org/10.3390/nu9050525

Malherbe, C. J., Willenburg, E., de Beer, D., Bonnet, S. L., van der Westhuizen, J. H., \& Joubert, E. (2014). Iriflophenone-3-C-glucoside from Cyclopia genistoides: Isolation and quantitative comparison of antioxidant capacity with mangiferin and isomangiferin using on-line HPLC antioxidant assays. Journal of Chromatography B, 951-952, 164-171. https://doi.org/10.1016/j.jchromb.2014.01.038

Oyanagui, Y. (1984). Reevaluation of assay methods and establishment of kit for superoxide dismutase activity. Analytical Biochemistry, 142(2), 290-296. https://doi.org/10.1016/0003-2697(84)90467-6

Porra, R. J., Thompson, W. A., \& Kriedemann, P. E. (1989). Determination of accurate extinction coefficients and simultaneous equations for assaying chlorophylls $a$ and $b$ extracted with four different solvents: verification of the concentration of chlorophyll standards by atomic absorption spectroscopy. Biochimica et Biophysica Acta (BBA) - Bioenergetics, 975(3), 384-394. https://doi.org/10.1016/S0005-2728(89)80347-0

Udem, C. G., Dahiru, D., \& Etteh, C. C. (2018). In vitro antioxidant activities of aqueous and ethanol extracts of Mangifera indica leaf, stem-bark and root-bark. Pharmacognosy Communications, 8(3), 119-124. http://dx.doi.org/10.5530/pc.2018.3.25

\section{Copyrights}

Copyright for this article is retained by the author(s), with first publication rights granted to the journal.

This is an open-access article distributed under the terms and conditions of the Creative Commons Attribution license (http://creativecommons.org/licenses/by/4.0/). 